\title{
O PAPEL DA FICÇÃO NO FILME ETNOGRÁFICO
}

\author{
Tatiana Helena de Souza Pereira ${ }^{1}$ \\ Universidade Estadual de Londrina \\ tatiana.hs@outlook.com \\ Prof ${ }^{\mathrm{a}}$. Carla Delgado de Souza \\ Univerdidade Estadual de Londrina \\ delgadodesouza@gmail.com
}

\section{RESUMO}

Pretende-se no presente trabalho problematizar as barreiras estabelecidas e a hierarquia vigente entre verdade e ficção nas produções humanas, para, em um segundo momento, pensar tal hierarquia na produção de filmes etnográficos, e mais especificamente no cinema indígena. Partindo da reflexão sobre filmes produzidos pelo projeto Vídeo nas Aldeias (VNA), criado em 1986 com o intuito de formar cineastas indígenas, para que estes tivessem autonomia sobre o contar de sua própria história e realidade, podemos levantar a questão sobre a ficção presente em tais produções, ao refletir que, no cinema indígena, uma representação dificilmente será percebida como algo não real, o uso de discursos ficcionais permitem explorar os mundos místicos do imaginário indígena, além de representá-los. Expondo, assim como o discurso ocidental, que opõe e delimita áreas entre verdade e ficção reduz as formas de representação de uma realidade. Já que conhecer o imaginário do outro é também uma forma de o conhecer mais profundamente ao ponto que, ao expô-lo, expõe-se também suas subjetividades.

Palavras-Chave: Ficção; Filmes etnográficos; Cinema indígena.

${ }^{1}$ Aluno/a do curso de Ciências Sociais da Uel (Universidade Estadual de Londrina).

\section{INTRODUÇÃO}

Quando pensamos na relação entre antropologia e cinema, torna-se necessário levar em consideração a história comum que possuem tais áreas do conhecimento em seus primórdios; mais especificamente na gênese cinematográfica, com a invenção dos primeiros instrumentos de captação de imagens, os papeis do cinema e da antropologia convergem-se em uma busca em comum, pois possuem a mesma alma: a do registro, a do conhecimento do "outro".

Não é fato desconhecido que sempre houve uma busca por conhecer e representar os infitinos "outros" existentes no mundo, porém, as formas dessa representação muito foram questionadas enquanto a sua legitimidade e objetividade. Perante ao constante debate sobre a objetividade nas ciências sociais, a antropologia, que em seu início muito se questionava pelas subjetividades presentes em seus relatos influenciados pela visão de mundo daqueles que os escreviam, percebe no uso da imagem uma forma de complementar e, de certa forma, comprovar e exemplificar aqueles povos antes retratados apenas por palavras. Cria-se, a partir de então, uma outra 


\section{SEMINÁRIO DE PESQUISA EM CIÊNCIAS HUMANAS - SEPECH \\ Humanidades, Estado e desafios didático-científicos \\ Londrina, 27 a 29 de julho de 2016}

forma de produzir e propagar um determinado conhecimento que há muito era monopolizado pela escrita.

Como coloca Ribeiro (2007) “A descrição etnográfica, etapa fundamental para a antropologia, não consiste apenas em ver, ou em ver e analisar, mas em mostrar, dizer ou escrever o que se vê, isto é o transformar o olhar em linguagem". A partir de tal constatação, podemos dizer que a riqueza presente nos materias imagéticos possibilitava à antropologia utilizar da imagem como uma outra formar de comunicar o seu olhar, uma outra forma de linguagem.

Assim, desde o seu surgimento, tais instrumentos - fotográficos e cinematográficos - passaram a ser usados na pesquisa antropológica com o intuito de trazer a ela um caráter mais objetivo. Ficava claro na época que "a incorporação de instrumentos de medição e de observação, nos estudos das sociedades e culturas, concedia à antropologia um caráter mais objetivo e, portanto, mais científico" (PEIXOTO, 1999, p. 93). O poder da imagem parecia estar na sua possibilidade de representação visual e na constatação de tal representação por todos aqueles que tivessem acesso a ela. A produção de imagens era percebida como uma "evidência direta e sem ambigüidade tornando-se uma realidade instantaneamente capturada e sem as distorções resultantes de falhas de observação e de memória ou de interpretação semântica" (PEIXOTO, 1999, p. 98).

Porém, nem o cinema estaria isento dos questinamentos sobre a objetividade que permeia o "mundo científico". Constata-se com o tempo que, como qualquer outra linguagem, o cinema e também a fotografia compõem as produções humanas que derivam de uma subjetividade e da visão de mundo de quem as produzem. Evidenciando que

o cinema é um modo de expressão como inil outros. [...]. Não há técnica para abordar a verdade. Só uma posição moral pode abordá- la. [...] A câmara é como uma pena de caneta, é uma bobagem qualquer, não tem nenhum valor se não temos algo a dizer (Rosselini apud Peixoto, 1999, p. 106).

E assim como o cinema, também o filme etnográfico, o real fruto do antigo casamento entre a antropologia e o cinema, também se percebe como mais uma "leitura possível, uma escolha, uma representação daquele que as produz" (PEIXOTO, 1999, p. 105). Como conclui Heusch (1962),

de uma maneira geral, a câmara não pode ser considerada como um observador sociológico objetivo, imparcial. É inútil continuar a multiplicar as exigências de não-intervenção; é vão sonhar com uma câmara invisível que registrará o fato social em seu estado nu, na sua pureza e sua espontaneidade original (PEIXOTO, 1999, p. 102).

A partir da seguinte questão - quando pensamos, mais especificamente, o filme ou cinema etnográfico, e levamos em conta sua dupla especificidade que o leva a buscar não apenas referências, mas tembém espaço em ambas as áreas de atuação, antropologia e cinema -, torna-se necessário problematizar o diálogo atual entre as duas áreas. Estas que, contemporaneamente, não flertam mais como no ínicio, trazem muitas vezes cobranças díspares em relação à produção do filme etnográfico. 


\section{SEMINÁRIO DE PESQUISA EM CIÊNCIAS HUMANAS - SEPECH \\ Humanidades, Estado e desafios didático-científicos \\ Londrina, 27 a 29 de julho de 2016}

Potanto, a questão de fato a ser abordada no presente trabalho refere-se ao filme etnográfico como uma produção que se encontra em uma liminaridade de áreas, e como ela lida com as refências que capta de ambas as áreas. Como consegue confluir a ética da pesquisa antropológica e as refências que traz o cinema atual enquanto possiblidade de criação, invenção e ficção. É sobre tal aspecto que me detenho no decorrer deste trabalho, com o intuito de entender as potencialidades das ferramentas cinematográficas atuais no exercício da antropologia, do estudo e registro do "outro".

\section{FICÇÃO, O ATO DE CONSTRUIR}

Para mim, como etnógrafo e cineasta, não existe quase barreira entre filme documentário e filme de ficção. O cinema, a arte do duplo, é sempre a transição do mundo real para o mundo imaginário, e etnografia, a ciência dos sistemas de pensamento dos outros, é um permanente cruzar de um universo conceitual para outro; ginástica acrobática, em que perder o pé é o mínimo dos riscos (ROUCH, 2003 Apud GONÇALVES, 2007, p. 2).

O filme etnográfico, enquanto produção, encontra-se em uma liminaridade de áreas, sendo elas a antropologia e o cinema, o que traz uma especificidade a sua definição. O clássico debate entre realidade e ficção presente no cinema, fica ofuscado na produção etnográfica, em um primeiro momento, pelo seu caráter de ciência, atribuindo-lhe, consequentemente, um ar de veracidade, no qual "pensar um filme etnográfico implica pensar-se a pesquisa e a ética da verdade como critério básico da legitimação da fidelidade da informação ali contida" (MENEZES, 2003, p. 89).

É com Jean Rouch que essa fronteira se embaça propositalmente, e começa-se a pensar na flexibilidade dos limites entre real e imaginário, além de pensar em como essas barreiras se transportam para as produções humanas, sejam elas da antropologia ou do cinema. Como diz Gonçalves (2007), a escolha em não opor ficção e realidade no trabalho de Rouch deriva certamente muito mais de sua sensibilidade antropológica do que de sua sensibilidade fílmica, ao ponto que, "essa condição da etnografia, de se ter acesso ao mundo do outro pela palavra do outro, sobre si próprio e sobre quem lhe pergunta como é o seu mundo, dá a etnografia a confiança de tomar o que as pessoas imaginam como sendo uma verdade, isto é, a verdade da etnografia" (GONÇALVES, 2007, p. 109 ).

Um mundo é construído por meio desses universos imaginativos e, no caso do filme etnográfico, o recurso fílmico e tudo que ele permite, inclusive a ficção, torna-se uma outra linguagem, possibilitando contar o que não pode ser contado de outra forma, assim, a linguagem fictícia é usada de forma que contribui com a modelação do real apresentado. A própria noção original de ficção, advinda da palavra fíccio, refere-se ao ato de construir, de modelar, e é esse sentido que se pretende pensar a ficção, não com o intuito de obscurecer ou de opor-se a verdade, mas de modelar, no sentido estrito da palavra, dar forma a algo, estabelecer contornos. Contornos esses delimitados também por uma construção coletiva, na qual a ficção, enquanto imaginário, traz a luz também os imaginários, desejos, sonhos coletivos que compõe o indivíduo construtor de uma ideia. Ela é, portanto, produto de um encontro, no qual as "subjetividades que emergem 


\section{SEMINÁRIO DE PESQUISA EM CIÊNCIAS HUMANAS - SEPECH \\ Humanidades, Estado e desafios didático-científicos \\ Londrina, 27 a 29 de julho de 2016}

são coletivas e polifônicas" (OPIRARI; TIMBERT, 1997, p. 394). Assim “ o real construído pelo artifício da imagem, uma ficção que longe de opor-se ao real, nos permite ao contrário construí-lo-coletivamente" (Idem, p. 396).

A ficção enquanto ato de construção permeia nossas vidas em todas as fases e esferas, quando nos permitimos sonhar, fazer planos, brincar, inventar, imitar, ter devaneios, ou seja, a todo momento ficcionamos nossas vidas. Há um processo dialético na construção da ficção quando pensamos que ela se constitui enquanto parte do real por fazer parte do nosso imaginário, este que, por sua vez, busca referências na realidade cotidiana. Portanto, nosso imaginário, nossa constante ficção, não está desvinculado do que se vive no real, das referências adquiridas e construídas, mas pelo contrário, ele opera na construção deste mesmo real.

Voltando a questão da hierarquia entre verdade e ficção presente nas produções humanas, e aqui mais especificamente nas produções de filmes etnográficos, há que se pensar em uma ética advinda da ciência cujas produções se fundamentam pela busca do real, em uma constatação o mais isenta de interferências possível. Tal busca pelo real reflete-se na produção de um filme etnográfico no qual "buscam transportar para a legitimação do discurso das imagens a legitimação do discurso da ciência e, no limite, do disrcurso de verdade da ciência como fonte de sua própria autenticidade" (MENEZES, 2003, p. 93).

Porém, o que de fato é esse real que buscam representar? Ao ponto que todo discurso produzido é uma construção direcionada, podemos pensar que "todo filme é uma ficção, não por ser uma criação da imaginação, não por ser uma invenção", mas pelo fato de que há uma estruturação realizada entorno do que se pretende mostrar e esconder. Há, como diz Menezes (2003), uma articulação de espaço e tempo, de imagens, de diálogos e sons na produção de um filme, seja ele etnográfico ou não, que submete-se a tal "modelação" do que se filma. Assim, um filme etnográfico é uma outra forma de se construir e apresentar um mundo, sendo que a exclusão da ficção não garante a veracidade, e o seu uso não torna uma produção isenta de conexão com o real. A ficção pode desempenhar, assim, o papel de provocar a verdade, na qual o outro, ao ter a possibilidade de improvisar e transbordar para a verdade também seus sonhos e seu imaginário, "deixa de ser apenas objeto de registro, mesmo que contribuindo para que este aconteça" (FREIRE, 2006, p. 6).

Em suma, um documentário se constrói com o sentido de "levar o espectador a ter contato e penetrar mais profundamente na realidade do outro" (FREIRE, 2006, p. 9), e conhecer o imaginário do outro é também uma forma de o conhece-lo mais profundamente, ao ponto que ao expô-lo, expõe também suas subjetividades.

O devir da personagem real quando ela própria se põe a ficcionar, quando entra em flagrante delito de criar lendas, e assim contribui para a invenção de seu povo ... Então o cinema pode se chamar cinemaverdade, tanto mais que terá destruído qualquer modelo de verdade para se tornar criador, produtor de verdade: não será um cinema da verdade, mas a verdade do cinema... isso que Jean Rouch entendia ao falar em cinema-verdade (Deleuze, 2005 Apud GONÇALVES, 2007, p. 137).

Portanto, a introdução da ficção de forma a agregar na construção de uma realidade é eficaz ao nos fazer entrar em contato também com as subjetividades do outro 


\section{SEMINÁRIO DE PESQUISA EM CIÊNCIAS HUMANAS - SEPECH \\ Humanidades, Estado e desafios didático-científicos \\ Londrina, 27 a 29 de julho de 2016}

retratado, e não apenas uma realidade que se contasta à primeira vista. Nesse sentido, "trata-se, pois, de problematizar não só a produção do filme etnográfico como uma questão investigável, mas também a forma como este estabelece a comunicação com o público, ou ainda como os públicos lhe atribuem sentido, como se apropriam deles e os integram nos seus sistemas de crença e de conhecimento do outro (RIBEIRO, 2007, p. 13).

Há, assim, a necessidade de se pensar nessa “compulsão do pensamento ocidental de desvalorizar ontologicamente a imagem e psicologicamente a função da imaginação como fomentadora de erros e falsidades" (GONÇALVES, 2007, p. 114). Tomando como exemplo o filme de Jean Rouch, "Moi, um noir", no qual os atores representam a própria realidade, a partir de um "cinema improvisação", o autor constata que "este jogo, extremamente simples e sofisticado ao mesmo tempo, que mistura atuação e registro cotidiano, revela muito mais sobre a existência e a subjetividade desses jovens africanos do que teria resultado um tratamento mais objetivo (Di Tella, 2001 Apud GONÇALVES, 2007, p. 126).

\section{CINEMA INDÍGENA}

"Somente um ato de resistência resiste à morte, seja sob forma de uma obra de arte, seja sob a forma de uma luta entre os homens" (DELEUZE, O ato da criação).

A notícia anunciando a gravação de uma série de ficção sobre a vida de jovens indígenas em Dourados (MS), mais especificamente sobre um grupo de Rap chamado Bro MC's que encontraram na música uma forma de mostrar a cultura do seu povo, nos faz pensar nas barreiras estabelecidas entre a realidade e a ficção presente nos filmes etnográficos.

Podemos problematizar a hierarquia presente na relação entre verdade e ficção, quando pensamos na ficção não como oposição ou forma de obscurecer o real, mas como uma outra forma de representação da realidade a partir de uma subjetividade específica. Desse modo, na produção citada acima não cabe dizer, por exemplo, que a série, por se tratar de uma ficção, não tem identificação com a realidade dos jovens indígenas, ao passo que a história contada reflete também um imaginário produzido a partir do que se vive e se faz presente. Nessa concepção, a ficção é compreendida como "um tratamento específico do mundo, inseparável daquilo que trata" (SAER, 1991, p. 2).

Pensando na produção realizada por grupos específicos (sejam eles textuais, imagéticos, representativos ou fictícios) como uma sintetização de seus respectivos sistemas de pensamento, o discurso que opõe verdade e ficção reduz as formas de representação de uma realidade. A etnoficção propõe-se, então, a pensar a ficção como um complemento e uma ferramenta na representação do real, e como ela não se desloca do meio em que foi produzida.

A partir da constatação de Deleuze (1999) sobre "o ato da criação" em que "um criador não é um ser que trabalha pelo prazer, um criador só faz aquilo de que tem absoluta necessidade", podemos pensar na necessidade atual de uma produção indígena como ato de resistência, que é colocada pelo autor como algo que tem a capacidade de 


\section{SEMINÁRIO DE PESQUISA EM CIÊNCIAS HUMANAS - SEPECH \\ Humanidades, Estado e desafios didático-científicos \\ Londrina, 27 a 29 de julho de 2016}

resistir, ou seja, de permanecer. Para ele, a singularidade de uma obra de arte é a capacidade de resistir até mesmo a morte. $\mathrm{O}$ contexto de morte há muito presente na realidade indígena, morte de suas ideias, de suas tradições, de seu meio natural, e de si mesmos, faz pensar como resistir é um ato de urgência. Assim pontuo Deleuze: aqui, a necessidade se faz presente, e toda suas produções se legitimam, como ato de resistência, como forma de permanecer.

Tal ideia se concretiza no filme "Já me transformei em imagem", de Zezinho Yube da etnia Hunikui, quando o pajé diz "eu já me transformei em imagem, mesmo que eu morra vocês vão me assistir, os meus netos e as novas gerações. O filme já foi assistido em vários lugares do mundo. Assim como o filme dos outros povos. O filme também incentiva outras terras Hunikui". Ao dizer que já se transformou em imagem, o pajé nos deixa claro que encontrou na produção fílmica sua forma de resistir, de permanecer. A produção hoje, portanto, de filmes realizados por indígenas surge de uma demanda desse povo em comunicar-se, em tornarem-se visíveis, e a produção audiovisual aparece como uma importante ferramenta de tal comunicação e também de transformação, na qual a imagem promove essa presentificação do ausente.

Partindo da reflexão então sobre filmes produzidos pelo projeto Vídeo nas Aldeias, com o intuito de formar cineastas indígenas, proporcionando que estes tenham uma autonomia enquanto ao contar de sua história e de sua realidade presente, podemos também levantar a questão sobre a ficção presente em tais produções, em que dificilmente indígenas perceberão uma representação como algo não real, o uso de dircusos ficcionais permite explorar os mundos místicos do indígenas, além de também representá-los.

A representação do mito nas produções fílmicas, o mito como organizador da experiência e também como construtor de sentidos, não deixa de ter uma semelhança com o conceito de ficção no que se refere ao ato de construir, modelar. Ao entender mito como algo construído, uma história, anexamos a ele um sentido de ficção, advinda de uma subjetividade, no caso coletiva. Ao representar o mito em uma produção fílmica, como parte do real enquanto algo que pertence a realidade representada, mas também como expressão de uma subjetividade coletiva, as fronteiras entre o real e a ficção se embaçam e torna-se possível pensarmos no "caráter duplo da ficção, que mescla, de um modo inevitável, o empírico e o imaginário" (SAER, 1991, p. 2). A ficção aqui se faz presente não como forma da narrativa, mas como conteúdo, sendo que o filme produzido, ao representar a realidade indígena, representa também a ficção intrínseca a ela.

Portanto, ao apreender a ficção como uma construção dada em um determinado contexto como parte e reflexo da realidade em que foi pensada, percebe-se que, embora a narrativa do filme seja construída, ela não deixa de representar a realidade, sendo o ponto de referência a partir do qual se constrói um imáginário. Logo, esteja a ficção reafirmando ou negando a realidade concreta, esta se faz presente como o eixo fixo de referência na construção de uma narrativa fictícia.

Assim podemos concluir que tal divisão entre realidade e ficção é uma norma do pensamento ocidental, que tende a separar e afastar os diferentes tipos de produção de conhecimento (científico, artístico, oral) - "ou se produz arte, ou se produz ciência". Porém, percebemos que o real é algo sinuoso, e assim também é a sua constatação. $\mathrm{O}$ potencial da imagem e, consequentemente, de um filme, é que há a comunicação com 


\section{SEMINÁRIO DE PESQUISA EM CIÊNCIAS HUMANAS - SEPECH \\ Humanidades, Estado e desafios didático-científicos \\ Londrina, 27 a 29 de julho de 2016}

todos os nossos sentidos, e nessa conversa nossas subjetividades claramente não ficam de fora.

\section{REFERÊNCIAS}

DELEUZE, G. O ato da criação. Edição brasileira: Folha de São Paulo, 1999.

FREIRE, M. Jean Rouch e a invenção do outro no documentário. Doc On-line, n. 03, 2007.

GONÇALVES, M. A. O real imaginado. Editora Topbooks, Rio de Janeiro, 2007.

MENEZES, P. Representificação: as relações (im)possíveis entre cinema documental e $\begin{array}{llllll}\text { conhecimento. } & \text { RBCS. } & \text { v. } & 18 & \text { n. } & 51,\end{array}$

PEIXOTO, C. E. Antropologia e filme etnográfico: Um travelling no cenário literário da antropologia visual. BIB, Rio de Janeiro, n. 48, 1999, p. 91-115.

PEIXOTO, C. E. Memória em imagens: uma evocação do passado. Ensaios em Antropologia Visual. RJ: Garamond, 2001.

RIBEIRO, J. da. S. Jean Rouch - Filme etnográfico e Antropologia visual. Doc On-line, n. 3, 2007.

SAER, Juan J. O Conceito de ficção. Punto de Vista, n. 40, Buenos Aires, 1991. 